\title{
A randomized, double-blind, placebo-controlled of vitamin D3 for Irish children with asthma
}

\author{
C.P. Kerley ${ }^{1,3}$, Katrina Hutchinson ${ }^{2}$, P. Greally ${ }^{3}$, D. Coghlan ${ }^{3}$ and B. Elnazir ${ }^{3}$ \\ ${ }^{1}$ Unversity College, Dublin, Belfield, Dublin 4, ${ }^{2}$ Biomnis Ireland, Sandyford business Estate, 3 Rock Rd, Dublin and \\ ${ }^{3}$ The National Children's Hospital, Tallaght, Dublin 24
}

We have recently reviewed that many mechanisms ${ }^{(1)}$ and human studies ${ }^{(2)}$ linking vitamin D deficiency (VDD) to asthma. Associations between vitamin D and both asthma/allergy appear stronger in children than adults ${ }^{(3)}$, with some even suggesting that childhood asthma may be caused by $\mathrm{VDD}^{(4)}$. Conversely, an alternative hypothesis suggests increased vitamin $\mathrm{D}$ status is associated with increased asthma/allergy incidence and severity ${ }^{(5)}$. In line with these opposing theories, several recent randomized trials of vitamin D supplementation in paediatric asthma have demonstrated inconsistent results. We wanted to assess the effects of vitamin $\mathrm{D}_{3}$ supplementation on subjective asthma measures, lung function, biomarkers of inflammation/allergy and self-reported exacerbation/ infection rate in Caucasian, asthmatic children residing at high latitude over the winter season.

After obtaining ethical approval, we conducted a 15 week double-blind, randomized, placebo-controlled trial of vitamin D supplementation $(2,000 \mathrm{IU} / \mathrm{d})$ in 44 urban, Caucasian children at high latitude (Ireland, $\left.53^{\circ} \mathrm{N}\right)$. Assessments were completed at baseline and after 15 weeks. The primary outcome was change in paediatric asthma control test (P-ACT). Secondary outcomes included lung function using computerized spirometry, subjective asthma control (GINA score, mini paediatric asthma quality of life questionnaire) and biochemical parameters of serum vitamin D $(25(\mathrm{OH}) \mathrm{D})$, allergy (total IgE), systemic inflammation (high sensitivity CRP), airway inflammation (eosinophil cationic protein), immunity (IgA) and bone homeostasis (parathyroid hormone, albumin corrected calcium, phosphate). Finally, parents/gaurdians completed a weekly diary during the trial regarding infection and exacerbation frequency.

39 children completed the trial. There was no significant differences in $25(\mathrm{OH}) \mathrm{D}$ levels at baseline. At follow up, 25(OH)D increased significantly in the vitamin $\mathrm{D}_{3}$ group (57 to $\left.104 \mathrm{nmol} / \mathrm{L}\right)$ compared to the placebo group $(53$ to $58 \mathrm{nmol} / \mathrm{L})$ (p $\left.<0.0001\right)$. There was no significant change in our primary endpoint (P-ACT) or secondary endpoints. However, there were non-significant, advantageous changes in the placebo group compared to the vitamin D group in subjective asthma control, inflammation and lung function, particularly $\mathrm{FEV}_{1} \%(+1.8 \mathrm{vs}-4.5 ; \mathrm{p}=0.06)$.

Vitamin $\mathrm{D}_{3}$ supplementation (2,000IU/d) for 15 weeks led to a significant increase in serum $25(\mathrm{OH}) \mathrm{D}$, but this change was not accompanied by significant changes in asthma control.

This work was supported by National Children's Hospital Foundation.

1. Kerley CP, Elnazir B, Faul J, Cormican L (2015) Pulm Pharmacol Ther [Epub ahead of print] doi: 10.1016/j.pupt.2015.02.010.

2. Kerley CP, Elnazir B, Faul J, Cormican L (2015) Pulm Pharmacol Ther [Epub ahead of print] doi: 10.1016/j.pupt.2015.02.004.

3. Goleva E, Searing DA, Jackson LP, et al. (2012) J Allergy Clin Immunol (2012) 129, 1243-51.

4. Litonjua AA, Weiss ST (2007) J Allergy Clin Immunol 120, 1031-5.

5. Wjst M (2012) Curr Opin Allergy Clin Immunol 12, 257-62. 